\title{
The Digestion of Pentosans in Hay by Sheep
}

\author{
By R. A. MARSHALL, Unit of Animal Physiology, Cambridge
}

\section{(Received 9 October 1948)}

In the diets of ruminants pentosans frequently represent an appreciable fraction of the total dry matter. No information seems to be available on the degree of digestion of pentosans at the successive levels of the alimentary tract. This has been determined in two sheep only, but the results appear to be of sufficient interest to warrant a note. Gray (I947) estimated the digestion of cellulose at various levels in the alimentary tract of the sheep by comparing the concentrations of lignin and cellulose in the ingesta; he showed that lignin was a satisfactory reference marker as, in the diet used, it proved to be indigestible. His technique was used in the following observations on the digestion of pentosans in sheep.

\section{METHODS}

Experimental animals. Two sheep, fed on chaffed meadow hay for 2-3 weeks, were killed without previous fasting. At post-mortem the alimentary tract was separated into its main anatomical divisions by ligatures; the contents of each organ were removed, mixed and a sample was dried at $100^{\circ}$; the samples were then ground and allowed to come to equilibrium with atmospheric moisture. For analysis portions of the air-dry samples were weighed, as the moisture content did not interfere in the estimation of the relative proportions of the constituents estimated.

Pentosan. This was estimated by the method of Kullgren \& Tyden (1929) in which furfural, formed by distillation with hydrochloric acid, is brominated with molybdate as catalyst and the excess of bromate is determined by iodometric titration; the second distillation recommended for use in the presence of hexoses was adopted. The results were calculated as xylan, since the predominating pentose unit in the pentosans of hay would be xylose (Norman, r937).

Lignin. This was estimated by the method of Norman \& Jenkins (I934a, b); it was found necessary to use the pre-treatment of Crampton \& Maynard (1938) in which the content of protein in the samples is reduced by digestion with pepsin- $\mathrm{HCl}$ before the analysis; appreciably lower values for lignin were obtained with this procedure. The ingesta of sheep may contain appreciable amounts of sand, and it was therefore essential to estimate the ash content of the preparations of lignin. The method used was as follows: I $\mathrm{g}$. of material was digested for about $18 \mathrm{hr}$. at $37^{\circ}$ with $40 \mathrm{ml}$. of a $2 \%$ solution of pepsin in $0.1 \mathrm{~N}-\mathrm{HCl}$; the residue was separated by filtration with mild reduced pressure through fine cotton lawn, washed well and then suspended in $10 \mathrm{ml}$. of $5 \%(\mathrm{v} / \mathrm{v}) \mathrm{H}_{2} \mathrm{SO}_{4}$ for $\mathrm{Ihr}$. at $100^{\circ}$; the residue was again separated in the same way and was then left for $24 \mathrm{hr}$. in $\mathrm{IO} \mathrm{ml}$. of $72 \%(\mathrm{v} / \mathrm{v}) \mathrm{H}_{2} \mathrm{SO}_{4}$ at room temperature; the product was diluted to $240 \mathrm{ml}$. with water (i.e. to $3 \%(\mathrm{v} / \mathrm{v}) \mathrm{H}_{2} \mathrm{SO}_{4}$ ) and heated for $2 \mathrm{hr}$. on the boiling water bath; the residue was then filtered off on filter paper, well 
washed, transferred from the paper into a crucible, dried at $100^{\circ}$, weighed, ashed and weighed again; the ash-free weight of lignin was recorded.

For the filtration of lignin through fabric a piece of fine cotton lawn was tied over the top of an ordinary glass funnel, the stalk of the funnel was connected to a filter pump, and the filtering surface was then dipped just below the surface of the fluid to be filtered; the suction drew off the solvent, and the lignin could then be washed back, without loss, into the beaker in which it had been digested.

\section{RESULTS}

The results of analyses of the ingesta from the various levels of the alimentary tract of the two sheep are given in Table $\mathbf{r}$.

Table I. Extent of digestion of pentosan at successive levels of the alimentary tract of the sheep

\begin{tabular}{|c|c|c|c|c|c|c|c|c|}
\hline & & & & Ingesta & from & & & \\
\hline & & Rumen & Omasum & Abomasum & $\begin{array}{c}\text { Small } \\
\text { intestine }\end{array}$ & Caecum & Colon & Fodder \\
\hline Lignin content & Sheep A & $21 \cdot 7$ & $25 \cdot 5$ & 23.6 & I $5 \cdot 3$ & $25 \cdot 7$ & 28.9 & I $7 \cdot 5$ \\
\hline (g./100 g. air-dry) & Sheep B & $2 I \cdot 6$ & 25.7 & $2 \times \cdot 5$ & $\mathrm{I} 8 \cdot \mathrm{I}$ & $27 \cdot 3$ & $28 \cdot 3$ & \\
\hline Pentosan content & Sheep A & $16 \cdot 2$ & I $7 \cdot 2$ & $16 \cdot 2$ & $10 \cdot 3$ & $15 \cdot 5$ & I 5.8 & 16.9 \\
\hline (g./100 g. air-dry) & Sheep B & $17 \cdot 3$ & I $6 \cdot 5$ & $14 \%$ & 10.3 & 14.8 & 147 & \\
\hline Pentosan digested & Sheep A & $22 \cdot 8$ & $30 \cdot 0$ & $29^{\circ} 0$ & $30 \cdot 0$ & $37 \cdot 3$ & $43 \cdot 6$ & - \\
\hline$(\%)^{*}$ & Sheep B & $16 \cdot 6$ & 33.7 & $30 \cdot 6$ & $4 I \cdot 0$ & $44^{\circ} \mathrm{O}$ & $46 \cdot I$ & \\
\hline
\end{tabular}

* Calculated as follows:

Percentage of pentosan digested in sample

$$
=\frac{\text { Ratio pentosan/lignin in hay }- \text { ratio pentosan/lignin in sample }}{\text { Ratio pentosan/lignin in hay }} \times 100 .
$$

In spite of the fact that the rumen contained much recently ingested material, a considerable degree of digestion had occurred in this organ. From the contents of the omasum, which may be taken to represent the end-product of rumen digestion, it is evident that considerably more than half of the total digestion of pentosan had occurred in the fore-stomachs. There was apparently no digestion of pentosan in the abomasum, but digestion continued in the small and large intestines.

\section{SUMMARY}

In two sheep, the pentosans of meadow hay were digested to the extent of $c .45 \%$. Most of the digestion of pentosan was accomplished in the rumen and omasum, and an appreciable amount was digested in the small and large intestines. It is doubtful whether any digestion of pentosan occurred in the abomasum.

\section{REFERENCES}

Crampton, E. W. \& Maynard, L. A. (1938). F. Nutrit. 15, 383.

Gray, F. V. (1947). J. exp. Biol. 24, I 5 .

Kullgren, C. \& Tyden, H. (r929). IngenVetenskAkad. Handl. no. 94. Quoted by C. Dorée (1947) in The Methods of Cellulose Chemistry, and ed. London: Chapman and Hall.

Norman, A. G. (1937). The Biochemistry of Cellulose, the Polyuronides, Lignin, etc., pp. 53-5. Oxford: University Press.

Norman, A. G. \& Jenkins, S. H. (1934a). Biochem. F. 28, 2 147.

Norman, A. G. \& Jenkins, S. H. (1934b). Biochem. F. 28, 2160. 